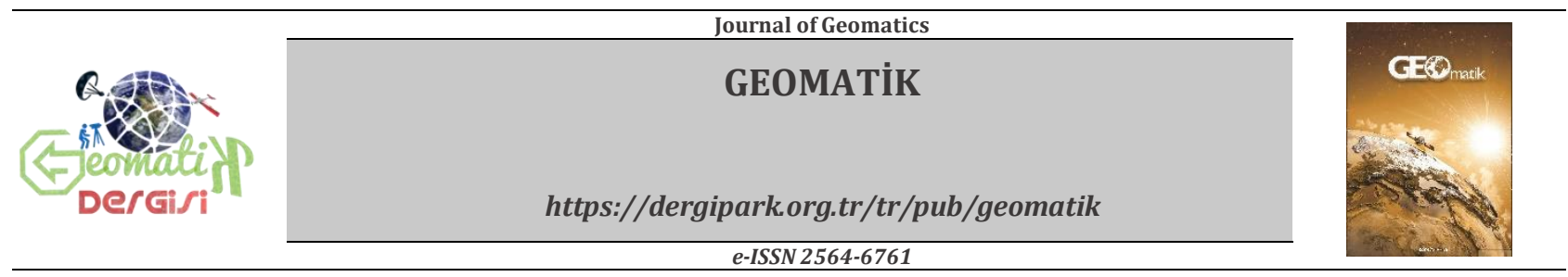

\title{
Ulusal Coğrafi Bilgi Sistemi Ulaşım Veri Temasının Katılımcı Coğrafi Bilgi Yaklaşımıyla Güncellenmesi
}

\author{
Berk Anbaroğlu*1, Naim Cem Güllüoğlu², Gökhan Bilgin1,2, Arif Çağdaş Aydınoğlu³ \\ ${ }^{1}$ Hacettepe Üniversitesi, Mühendislik Fakültesi, Geomatik Mühendisliği Bölümü, Ankara, Türkiye \\ 2 Çevre ve Şehircilik Bakanlı̆̆ı, Coğrafi Bilgi Sistemleri Genel Müdürlüğ̈̈, Ankara, Türkiye \\ ${ }^{3}$ Gebze Teknik Üniversitesi, Mühendislik Fakültesi, Harita Mühendisliği Bölümü, Gebze, Türkiye
}

Anahtar Kelimeler
INSPIRE
TUCBS
Ulaşım
Geoportal
Açlk Veri

\begin{abstract}
ÖZ
Bu makalede, katılımcı bir yaklaşımla güncellenen Türkiye Ulusal Coğrafi Bilgi Sistemi (TUCBS) Projesi 'ulașım' coğrafi veri teması incelenmektedir. Ulașım teması örneğiyle veri yönetiminde literatürdeki farklı yaklaşımlar irdelenmiş, ilgili kurumların veri üretim ve paylaşım durumu yapılan anket çalıșması ile analiz edilmiştir. Bu çalışmada aynı zamanda 2013 yılında belirlenen TUCBS ulaşım teması ile katılımcı yaklaşımla 2018'de güncellenen tema arasındaki benzerlikler ve farklılıklar da tespit edilmiştir. Güncellemeler kapsamında detay tipi (nesne tipi) sayısının 50'den 131'e çıktığı, ön tanımlı veri tablosu (codelist) sayısının 33'ten 42'ye çıktığı, 26 tane nesne tipinin ve 17 tane ön tanımlı veri tablosunun da her iki çalıșmada ortak olduğu tespit edilmiștir. Katılımcı bir yaklaşımın coğrafi veri altyapılarının güncellenmesinde gerekli olduğu, ancak halen istenilen düzeyde olmadığı da görülmektedir. Ulaşım temasıyla ilgili tüm paydaşların ortak aklıyla belirlenen standartların daha ișlevsel olacağı ve hızlıca uygulamaya konulabileceği değerlendirilmektedir.
\end{abstract}

\section{Updating Transportation Data Theme of National Spatial Data Infrastucture with Participatory Geographic Information}

\author{
Keywords \\ INSPIRE \\ TUCBS \\ Transportation \\ Geoportal \\ Open Data
}

\begin{abstract}
The purpose of this article is to examine the 'transport' geographic data theme of the Turkish National Geographic Information System (TUCBS) Project which is updated with a participatory approach. In this context, the results of the survey conducted with the representatives of the institutions, which provide a better understanding of the geographical data production and sharing status of the institutions, are analysed. In this study, similarities and differences between the TUCBS transport theme that is initially determined in 2013 and updated in 2018 with the participatory approach is also identified. Within the scope of the updates, it is determined that the number of feature types increased from 50 to 131, the number code lists increased from 33 to 42 and 26 feature types and 17 code lists remain common in both studies. It is necessary to update the spatial data infrastructures with a participatory approach, however, it is still not at the desired level yet. It is foreseen that the contribution of all the stakeholders in standardizing the transportation theme will make the standards be more operational.
\end{abstract}




\section{GíRiş}

Coğrafi bilgi birikiminin artırılması ve veriye dayalı planlama ve politikaların oluşturulması kapsamında veri altyapılarının kurulması son yıllarda öncelikli araştırma konusu olmuştur. Veri altyapılarının en yaygın bilinenlere örnek olarak Avrupa'da INSPIRE Direktifi ile gerçekleștirilen çalışmalar, Amerika, Asya ve Afrika ülkelerinde Küresel Coğrafi Veri Altyapısı'nın kapsamındaki çalışmalar verilebilir (Craglia ve ark., 2012).

Avrupa coğrafi veri altyapısının kurulmasını hedefleyen "Infrastructure for Spatial Information in Europe (INSPIRE)” Direktifi 15 Mayıs 2007 tarihinde Avrupa Parlementosu'nun kabulüyle yürürlüğe girmiştir (INSPIRE, 2007). Bu kapsamda, coğrafi verinin üretilmesi ve paylaşılmasının belirli standartlar çerçevesinde gerçekleştirilmesi hedeflenmektedir. Ulaşımdan arazi örtüsüne, enerjiden idari birim sınırlarına kadar 34 farklı tema için coğrafi veri üretim ve paylaşım standartlarının belirlenmesi ile coğrafi olaylar bütüncül bir yaklaşımla ele alınabilmektedir.

INSPIRE Direktifi uygulanmasının iki önemli açıdan fayda sağlaması öngörülmektedir. İlk olarak, farklı coğrafi veri katmanlarının etkin bir șekilde birlikte çalışabilirliği sağlanabilecektir. Böylece coğrafi olguların bütünleşik bir biçimde ele alınması mümkün olmaktadır. İkinci olarak, coğrafi veri dökümantasyonu ve metaverinin de coğrafi veri ile birlikte erişilebilirliği sağlaması ve mükerrer veri üretiminin önüne geçmesidir (Aydinoğlu ve Kara, 2019).

Türkiye Ulusal Coğrafi Bilgi Sistemi (TUCBS) altyapısının tesisi ve coğrafi verinin ulusal düzeyde üretimi ile paylaşımına yönelik standartların belirlenmesi görevleri Çevre ve Şehircilik Bakanlığı bünyesinde Coğrafi Bilgi Sistemleri Genel Müdürlüğü'ne verilmiştir (URL 1; URL 2). Bu kapsamda Coğrafi Bilgi Sistemleri Genel Müdürlüğü tarafından 2013 yılında 10 adet ulusal coğrafi veri temasına ilişkin standartlar belirlenmiştir (URL 3; URL 4). Ancak bahsi geçen standartların zamanla değişen güncel ihtiyaçları karşılamamasından dolayı standartların güncellemesine ve genişletilmesine ihtiyaç duyulmuştur. Bu sebeple paydaş kamu kurumlarının katılımı ile 2018'de gerçekleştirilen toplantılarda önceden belirlenen standartlar güncellenmiştir.

Coğrafi Bilgi Sistemleri Genel Müdürlüğü'nün standart belirleme çalışmaları kapsamında 2019 yılında 8 yeni veri teması için de veri tanımlama dokümanları hazırlanmıştır (URL 3). Bu veri temaları Arazi Kullanımı, Toprak, Korunan Alanlar, Doğal Risk Bölgeleri, Teknik Altyapı, Enerji Kaynakları, Maden Kaynakları ve İnsan Sağlığı ve Güvenliği'dir. Bu güncelleme çalışmaları sırasında katılımcı bir yaklaşım benimsenmiştir. Nitekim böyle bir yaklaşımın gerekliliği Güney ve ark. (2015) tarafindan da vurgulanmaktadır.

Gerek evimiz ve işimiz arasında gerçekleştirdiğimiz yolculuklarımızın gerekse tedarik zincirinin önemli bir halkası olan ulaşım ağlarının katılımcı ve veriye dayalı bir şekilde olușturulması, şehirlerin gelișmesinde ve etkin yönetiminde önemli bir rol oynamaktadır (Hickman ve Dean, 2018). Ulaşım planlaması ve yönetimi, sadece ulaştırma sektörü ile değil, aynı zamanda diğer ekonomik sektörlerle de iç içe bir yapıdadır. Örneğin sağlık sektöründe, yeni bir yol yapımının, bölgede ormancılığı artırması ve ağaç kesiminin önünü açması gibi çevresel ve sosyal koşullar üzerinde yaptığı etkilerin, yolun çevresinde bulunan köylerdeki enfeksiyonların yayılmasını nasıl artırdığı ve dolayısıyla insan sağlığını nasıl etkilediği araştırılabilir (Eisenberg ve ark., 2006). Enerji sektöründe ise, şehir içi raylı ulaşımda enerji verimliliğinin arttırılması için zaman çizelgelerinin analizi veya daha verimli sürüş yöntemleri incelenebilir (Yang ve ark., 2016).

Ulaşım planlaması ve yönetimi için bütünleşik bir yaklaşımın gerekliliği 2014-2023 Ulusal Akıllı Ulaşım Sistemleri Strateji Belgesi'nde (Ulaştırma, Denizcilik ve Haberleşme Bakanlığl, 2014) ve 20202023 Ulusal Akıllı Şehirler Stratejisi ve Eylem Planı'nda (Çevre ve Şehircilik Bakanlığı, 2019) vurgulanmaktadır. Bütünleşik bir ulaşım planlaması ve yönetiminin sağlanması amacına ulaşmak için farklı kurumların, farklı ihtiyaçlarının ve farklı veri üretim süreçlerinin anlamsal bir biçimde ele alınması gerekmektedir (Ballis, 2006; Ulutaş ve ark., 2016). Farklı kurumlarca toplanan ve/veya üretilen ulaşım verisinin anlamsal açıdan farklılıklar da içerebileceği göz önüne alındığında, bunların tek bir kaynaktan ontolojiler yardımıyla paylaşılmasının gerekebileceği de belirtilmektedir (Gunay ve ark., 2014).

Karmaşık bir süreç olan ulaşım altyapısı planlamasının ilk ve en önemli ayaklarından biri mevcut durumun en güncel veri ile tespit edilebilmesidir. Verinin karar verme süreçlerinde doğrudan etkili olduğu "performans tabanl planlama" yaklaşımı da özellikle Amerika Birleşik Devletleri'nde yıllardır başarıyla uygulanmaktadır (Pickrell ve Neumann, 2001). Başarı artışının temel dayanağının da ulaşımla ilgili verinin katılımcı bir yaklaşımla oluşturulması ve açık olarak paylaşılması olduğu değerlendirilmektedir (Proffitt ve ark., 2019).

Katılımcı bir yaklaşımda her ne kadar ulaştırma alanında çalışan kurum ve şirket temsilcilerinin bulunması gerekli olsa da, yeterli değildir. Bir ulaşım sisteminin en önemli paydaşı olan yolcuların görüşlerinin de planlamaya dâhil edilmesi şüphesiz ki önem arz etmektedir (Kesten ve Ögüt, 2014).

Bu çalışmanın amacı da, INSPIRE'ı temel alan ve 2013 yllında belirlenmiş olan Türkiye Ulusal Coğrafi Bilgi Sistemi (TUCBS) ulaşım temasının 2018 yılında katılımcı bir yaklaşım ile gerçekleştirilen güncelleme çalışmalarını teknik ve bilimsel açıdan ele almaktır. Makalenin ikinci bölümünde literatür incelemesi sunulacaktır. Üçüncü bölümde, TUCBS ulaşım veri teması kapsamında gerçekleştirilen çalışmalar sunulacaktır. Dördüncü bölümde, INSPIRE 
Direktifinin ulaşım sektöründe uygulanması için gerekli koşullar tartışılacaktır. Beşinci bölümde 2013 yılında belirlenen ulașım temasının, 2018 yılında katılımcı bir yaklaşımla güncellenmiş olan sürümü ile benzerlikleri ve farklılıkları sunulacaktır. Son olarak, altıncı bölümde çalışmanın sonuçları tartışılacaktır.

\section{YÖNTEM}

\subsection{Literatür Araştırması}

Aynı coğrafi veri setinin farklı kurumlarca üretilmesini ve güncellenmesini önlemek ve aynı zamanda coğrafyanın bütüncül bir yaklaşımla ele alınmasını sağlamak, hem araștırmacılar hem de karar mercileri için önemlidir. Bu kapsamda kurumlar verilerini 'geoportal' adı verilen araçlar ile kullanıma sunmaktadır. Böylece, farklı planlamalar ve idari birimler arasındaki iletişimin en iyi şekilde sağlanması ve coğrafi web servislerine erişim hedeflenmektedir (Goodchild ve ark., 2007; Tait, 2005). Geliștirilen web servislerinin güncel tutulması da başlı başına bir çalışma odağıdır (Yllmaz ve Canıberk, 2018).

Ulaştırma alanında hem farklı idari seviyelerde (yerel, bölgesel ve ulusal) hem de farklı planlama vizyonlarında (kısa, orta ve uzun vadeli) değerlendirmeler yapılabilmesi için verinin güncelliği ve doğruluğu büyük önem arz etmektedir (Karlaftis ve Kepaptsoglou, 2012; Proffitt ve ark, 2019). Böylece, erişilebilirlik, güvenlik, ulaşım planlamasında çevresel etkiler ve yeni projelerin değerlendirilmesi gibi birçok farklı konunun 'veri'ye dayalı bir yapıda incelenmesi mümkün olmaktadır.

Ülkemizde ihtiyaç duyulan veriye ve veri yapısına erişim için Coğrafi Bilgi Sistemleri Genel Müdürlüğü ${ }^{1,2}$ ve Harita Genel Müdürlügü ${ }^{3}$ tarafından sunulan geoportallar kullanılabilir. INSPIRE uyumlu geoportallar4 aracılığıyla da Avrupa'daki farklı ülkelerin coğrafi veri altyapılarına erişim mümkün olmuştur.

Amerika Birleşik Devletleri'nde ulaştırma projelerinin değerlendirilmesinde kullanılan "performans tabanlı planlama" yaklaşımında yedi temel öğe vardır. Bu yaklaşımlardan, sistemin sürekliliğinin sağlanması için belki de en önemlisi "izleme ve geri bildirim"dir. Her ne kadar, "iletişim ve sonuçların raporlanması" ayrı bir öğe olarak değerlendirilse de, aslında "izleme ve geri bildirim" öğesinin doğal bir sonucudur (Pickrell ve Neumann, 2001). Bu iki öğenin de etkin bir şekilde gerçekleşmesi için katılımcı bir yaklaşıma ihtiyaç duyulmaktadır.

Geri bildirim süreçlerinin etkin olmadığı durumlarda sistemin sürekliliği sağlanamayabilir. Bütüncül bir yaklaşımla ulaşım planlaması öneren İtalyan SNIT örneğinde, uygulamayı yürütecek olan kurumlar sürece etkin bir şekilde dâhil

${ }^{1}$ https://www.geoportal.gov.tr/

${ }^{2}$ https://tucbs-public-api.csb.gov.tr/tucbs olmamışlardır. Pratik ile teorinin etkin bir entegrasyon süreciyle desteklenmediği çalışmaların, sürdürülebilir olamayacağı da belirtilebilir (Borzacchiello ve ark., 2009). Dolayısıyla, ulaştırma alanında toplanan verinin nasıl saklanması ve paylaşılması gibi işlemleri içeren bilişim altyapısı yanı sıra, uygulamada da önerilen yaklaşımın benimsenmesini destekleyecek bir işlevsel süreç gereklidir.

Geoportal üzerine yapılan çalışmalar esasında gelişen web teknolojilerinin bir ürünüdür ve verinin hızlı bir şekilde servis edilebilmesine olanak sağlamaktadır. Ancak bu servislerin çok daha hızlı bir şekilde kesintiye uğrayabileceği de unutulmamalıdır. Açı veri alanında en bilinen örneklerden biri olan Amerika Birleşik Devletlerinin "data.gov" sitesi, bütçe kısıtlarından ötürü Aralık 2018'de askıya alınmıştır ve erişim sağlanamamıştır. $\mathrm{Bu}$ tür sistemlere erişimin birçok nedenle kesintiye uğrayabilmesi çevrimiçi sistemleri hassas kılar.

\subsection{Durum Tespiti}

TUCBS ulaşım teması güncellenmesi kapsamında, katılımcı bir yaklaşım benimsenerek tüm ulaşım modlarını (karayolu, demiryolu, havayolu ve deniz ulaşımını) temsil eden kurum temsilcileri Ekim-Aralık 2018 tarihlerinde gerçekleștirilen toplantılara davet edilmiştir. Ulaşımla ilişkili veri üreten veya kullanan İl Özel İdareleri ve Büyükşehir Belediyeleri gibi yerel yönetim temsilcileri ile Karayolları Genel Müdürlüğü ve Harita Genel Müdürlüğü gibi merkezi yönetim temsilcileri de toplantılara davet edilmiştir. Böylece mümkün olduğunca farklı bakış açılarını temsil edebilecek 15 farklı kurumun temsilci göndermesi için resmi talepte bulunulmuştur ve toplamda 24 temsilci toplantılara katılım göstermiştir. Kimi kurum temsilcileri toplantıların tamamına ve bazı kurum temsilcileri de sadece belirli toplantılara katılıp katkı verme imkânı bulmuştur.

Toplantılarda öncelikle projenin kapsamı tanıtılmıștır. Haftada bir gün yüz yüze gerçekleştirilen toplantılarda temel kavramlar ve terminoloji tanitıldıktan sonra, referans sistemleri, veri kalitesi, metaveri ve veri paylaşımı gibi konular uzmanlar tarafından sunulmuştur.

Her ne kadar birçok çalışmada birlikte çalışabilirliğin önemi, mükerrer veri üretiminin önlenmesi ve veri kalitesi gibi kavramlar üzerinde durulsa da, katılımcıların bu konuları bizzat tecrübe etmesinin faydalı olacağı anlaşılmıştır. İlgili kurumlar tarafından üretilen veriler toplanmış olup, tüm katılımcıların incelemesine sunulmuştur. Elde edilen çıktılardan bir tanesi Şekil 1'de gösterilmiștir.

Çalışmanın belki de en önemli kazanımlarından biri de kurum temsilcilerinin veri standardizasyonunun önemini bizzat tecrübe etmiş olmalarıdır. Örnek olarak, hem bir İl Özel İdaresi

\footnotetext{
${ }^{3}$ https://geoportal.harita.gov.tr/

${ }^{4}$ http://inspire-geoportal.ec.europa.eu/
} 
tarafindan hem de Orman Genel Müdürlüğü tarafından sayısallaştırılmış bir yol verisi katılımcıların dikkatini çekmiştir. Bu yolu İl Özel İdaresi 'köy yolu' olarak değerlendirirken, Orman Genel Müdürlügü'nün ise 'orman yolu' olarak değerlendirdiği tespit edilmiştir. Böylece kurumlar arasındaki olası kavram karmaşaları (bir yol hangi durum(lar)da köy/orman yolu olur) ve mükerrer veri üretiminin neden olduğu kaynak israfi bizzat katılımcılar tarafından tecrübe edilmiştir.

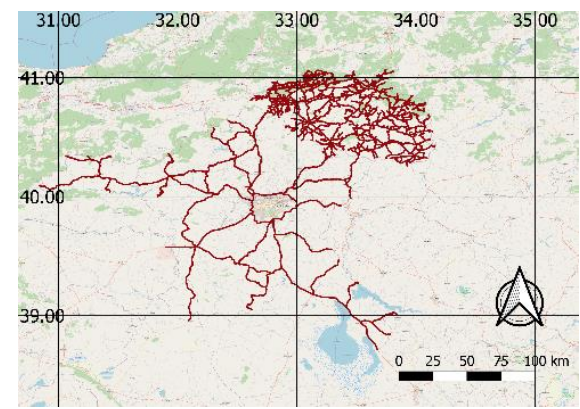

Şekil 1. Karayolu alt bileşeni, yol orta çizgisi veri örneği

Çalışmanın ikinci aşamasında da mevcut coğrafi verinin ve özel olarak da ulaşımla ilgili yapının daha iyi anlaşılması için bir anket tasarlanmıştır. Bu anketteki sorular, Tablo 1'deki gibi üç gruba ayrılmıștır ve anket katılımcılarla web üzerinden paylaşılmıştır. Anket katılımcıları genellikle karayolu trafik ağıyla ilgilenmektedir.

Tablo 1. Ulaşım teması için katılımcılara yöneltilen anket

\begin{tabular}{|c|c|}
\hline No & Soru \\
\hline 1 & $\begin{array}{l}\text { Kaç farklı coğrafi veri } \\
\text { çalışıyorsunuz? }\end{array}$ \\
\hline 2 & Veri setlerinize ait meta-veri tutuyor musunuz? \\
\hline 3 & $\begin{array}{l}\text { Veri kalitesini değerlendirdiğiniz ek bir iş } \\
\text { süreciniz var mı? }\end{array}$ \\
\hline 4 & $\begin{array}{l}\text { Yol katmanında kaç farklı öznitelik } \\
\text { bulunmaktadır? }\end{array}$ \\
\hline 5 & Veriyi hangi formatta paylaşıyorsunuz? \\
\hline 6 & $\begin{array}{l}\text { Veriyi diğer Kurumlarla genelde nasıl } \\
\text { paylaşıyorsunuz? }\end{array}$ \\
\hline 7 & Veriyi internet üzerinde paylașıyor musunuz? \\
\hline 8 & $\begin{array}{l}\text { Geçtiğimiz üç ayda yaklaşık olarak kaç kere } \\
\text { bașka bir Kurumdan veri talep ettiniz? }\end{array}$ \\
\hline 9 & $\begin{array}{l}\text { Talep edilen veri ortalama kaç günde elinize } \\
\text { geçer? }\end{array}$ \\
\hline 10 & $\begin{array}{l}\text { Geçtiğimiz üç ayda yaklaşık olarak kaç kere } \\
\text { başka bir Kurumla veri paylaştınız? }\end{array}$ \\
\hline 11 & $\begin{array}{l}\text { Talep edilen veriyi ortalama kaç gün içinde } \\
\text { paylaşıyorsunuz? }\end{array}$ \\
\hline
\end{tabular}

Ankete katılan kurum temsilcilerinin sadece 'karayolu' üzerine çalışıyor olmasının temel nedeni de diğer ulaşım modlarının sorumluluğunun genelde tek bir kuruma bağlı olmasıdır (ör. demiryolu ağı sadece TCDD'nin sorumluluğundadır).
Birinci soruda kurumların üzerinde çalıştıkları katman sayılarında üç katmandan 132 katmana kadar büyük farklılı olabileceği görülmektedir. İkinci soruda ise, kurumlarımızın yarısının metaveri tuttuğu, diğer yarısının ise tutmadığı görülmektedir. Kurumlarımızın üçte ikilik bir çoğunluğunun ise veri kalitesinin değerlendirilmesi üzerine ek bir iş süreci gerçekleştirdiği görülmektedir. Dördüncü sorudan ise yol katmanında tutulan öznitelik sayısının da kurumlarımızca farklılık gösterdiği görülmektedir (Şekil 2). Burada belirtilmesi gereken bir durum ise, bütün kurumlarımızın 'yol'u çizgi yapısı ile ifade etmesidir.

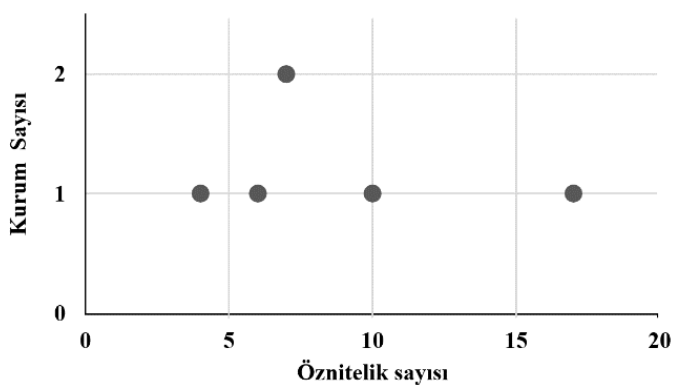

Şekil 2. Yol katmanında bulunan öznitelik sayısı

Veri paylaşımı üzerinde durulan ikinci grup sorularda tespit edilen ilk sonuç, bütün kurumlarımızın açık bir standart olan ShapeFile (SHP) ile coğrafi verilerini paylaşabilmesidir. Bunun yanında KML, Geopackage, GeoJSON gibi açık standartlar ile de coğrafi veri paylaşılabilmektedir. Belirli lisanslı yazılımlarla uyumlu NCZ, MDB ve GDB gibi formatlarda da coğrafi verinin paylaşllabileceği belirtilmiştir. Bu soruda kurum temsilcileri birden çok formatta veriyi paylaşabileceklerinden dolayı, birden çok format seçme hakkı da tanınmıştır. Açık standartları dayalı veri paylaşım ortamının olușturulmasının coğrafi veri ile ilișki sektörleri olumlu etkileyeceği değerlendirilmektedir (Varol ve Şanlıoğlu, 2017).

Anketin altıncı sorusunda, coğrafi verinin hangi şekilde paylaşıldığı incelenmiştir. Kullanılan web servisleri ayrıștırılmadığından, veri paylaşımında web teknolojilerinin yarı yarıya kullanımı dikkat çekmektedir. İlerleyen yıllarda bu anket yapıldığında, veri paylaşımın büyük çoğunlukla web teknolojileri ile sağlanacağı ön görülmektedir.

Anketin yedinci sorusunda ise verinin genel olarak internet üzerinden paylaşıldığ görülmektedir. Ancak, sadece bir kurumun verisini halka açık olarak paylaşması ve kurumlar arası veri paylașımında bürokratik bir süreç olan 'protokol' gerçekleştirilmesi gerekliliğinin, ulaştırma alanında çalışan paydaşları olumsuz etkileyebileceği değerlendirilmektedir. Ulaştırma altyapısının genel olarak bir kamu hizmeti olduğu ve 'gizlilik' teşkil edecek bir niteliği de bulunmadığı düşünülürse, kurumların ürettikleri veriyi etkin ve halka açık bir şekilde paylaşmalarının ulaştırma sektörünü daha da güçlendireceği öngörülmektedir. 
Son grup sorularda ise pratikteki veri paylaşım süreci hakkında daha detaylı bilgi edinilmesi hedeflenmiştir. Yakın bir zaman olarak değerlendirebilecek 'son üç ay'llk bir dilimde, kurumlarımızın üçte ikilik bir çoğunluğu başka bir kurumdan veri talebinde bulunmuştur. Bu da veri paylaşım ihtiyacının pratikte karşıllı̆ı olduğunun en büyük göstergesidir. Bu üç aylık süreç uzatıldığında, diğer kurumlardan ihtiyaç duyulan verinin de artacağı belirtilebilir.

Anketin dokuzuncu sorusunda ise, verinin temin edilme süresinde farklılıklar göze çarpmaktadır. Kimi kurumlar veriyi talep ettikleri gün temin edebilmekteyken, kimi kurumlar için bu süreç 15 günü bulabilmektedir. Genel olarak ise, bir haftallk bir süreçte verinin temin edilebildiği görülmektedir. Anketin son sorusunda ise kurumlarımızın üçte ikilik bir çoğunluğunun kendilerinden istenen veriyi bir hafta içerisinde diğer kurumla paylaştıkları görülmektedir. İstenilen verinin temin edilme süresi ile paylaşılma süreleri arasındaki ilişkiyi gösteren karşılaştırmalı grafik Şekil 3'te belirtilmiştir.

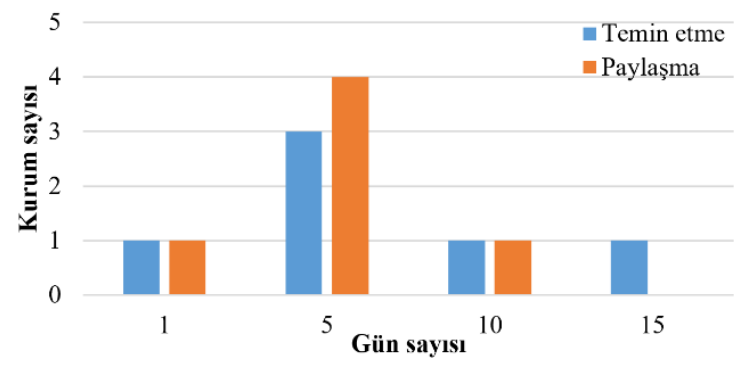

Şekil 3. Verinin temin edilme ile paylaşılması süreleri arasındaki ilişki

Son üç aylık süreçte, kurumlarımızın sadece üçte biri başka bir kurumla veri paylaşmamışken, büyük bir çoğunluğun veri paylaşımında bulunduğu görülmüştür. Bu veri paylaşımının da iki ile beş kurum arasında değiştiği belirtilmiştir. Böylece, veri paylașımının kurumlarımız açısından gerekliliğine ve yaygınlığına yapılan vurgu daha da desteklenmiş olmaktadır.

\subsection{Katılımcı Yaklaşım ile Ulaşım Veri Modelinin Belirlenmesi}

Katılımcı bir yaklaşımla gerçekleştirilen TUCBS toplantılarında, ulaşımla ile ilgili coğrafi nesne tiplerinin (detay tipi, feature type) ne oldukları, nasıl adlandırılmaları gerektikleri ve benzer şekilde bu coğrafi detayların özniteliklerinin belirlenmesi gerçekleştirilmiştir. Yaklaşık üç ay süren oturumlar boyunca paydaş kurumlar veri yapısına ilişkin beklenti ve ihtiyaçlarını belirtmişlerdir. Haftanın belirli bir gününde gerçekleştirilen oturumlarda kurum temsilcilerinin metaveri, veri kalitesi, veri teslimi, veri üretimi ve kartografik gösterim gibi farklı konularda görüşlerine başvurulmuştur.
Çalışmanın ilk aşamalarında, bu veri altlıklarının navigasyon odaklı düșünülmesi gerektiği vurgulanmıștır. Nitekim navigasyon için yol kesişim düğümlerinin, yol kuralları (ör. U-dönüşü yapılamaz) ile anlamlandırılması gerekmektedir. $\mathrm{Bu}$ kapsamda, Ulaştırma Bakanlığı'nın gerçekleştirmiş olduğu "Ulusal Ulaştırma Portalı"5 ve açık bir sistem olan Open Source Routing Machine (OSRM) ${ }^{6}$ ile bu tür navigasyon temelli çalıșmaların sağlanabildiği de tespit edilmiştir.

Önemli bir diğer nokta olarak, yol verisi tutulurken, 'yol alanı' ve 'araç taşıt alanı' adı altında iki adet poligon katmanının tutulması gerektiği belirtilmektedir (INSPIRE 2014). Bu durum, coğrafyanın bütüncül bir yaklaşımla ele alınması konusunda destekleyici niteliktedir. Ancak, poligon katmanı üreten bir kurumun olmaması da bu sürecin nasıl işletilebileceği konusunda belirsizlik yaratmaktadır.

INSPIRE uyumluluğu kapsamında ihtiyaç duyulan poligon katmanlarının sağlanması için belki de en önemli gereksinim, altyapı çalışmalarıyla ilgilenen kişilerin de güncelleme sürecine dahil olmasını sağlamaktır. Böylece, altyapı alanında çalışan paydaşların görüşleri ve bu konuda ihtiyaçları daha net anlaşılabilir. Nitekim, 'araç taşıt' ve 'yol trafik' alanlarının belirlenmesi ile birlikte alt yapı ile ilgilenen kurumlar en büyük faydayı sağlayacaklardır (Chen ve Cohn, 2011).

Bunların yanında bisiklet yolu güzergahlarının ve kurulacak olan istasyonların konumlarının da belirlenmesi için doğru ve güncel trafik alanı verisine ihtiyaç duyulmaktadır. Son olarak, yaya navigasyonun etkin bir şekilde gerçekleştirilebilmesi için de kaldırımların yolun hangi tarafında bulunduğunun bilinmesi gerekmektedir. Bütün bu alanlarda çalışan kişilerin görüşleri büyük önem arz etmekte olup, toplanması maliyetli olacak bu verinin nasıl ve kimler tarafından kullanılacağının bilinmesi, verinin üretilmesinde motivasyon oluşturacaktır.

CCalışmanın son oturumlarında ise, diğer veri temalarının da şekillenmesiyle birlikte, ulaşım veri temasına ait coğrafi nesnelerin kartografik gösterimine ilişkin farklı beklentiler ortaya konulmuştur. Veri formatı için eXtensible Markup Language (XML) tabanlı açık veri yapısı olan Geography Markup Language (GML) formatı genel olarak kabul görürken kartografik gösterimin tanımlanması için de Styled Layer Descriptor (SLD) yapısı öne çıkmıștır. Farklı kurumların aynı veri için farklı kullanım senaryolarına sahip olmaları sebebiyle tüm kurumların ihtiyaçlarını karșılayabilecek kapsayıcılıkta ön tanımlı ortak bir SLD şablonunun oluşturulmasının zor olacağı anlaşılmıştır. Ancak yine de çalışma sonunda tüm nesne tipleri için (örneğin karayolu orta çizgisi) bir öznitelik alanına bağlı şekillenen (örneğin karayolu tipi) gösterim türü SLD formatı ile tanımlanmıștır (örneğin karayolu nesnesinin tipine göre değișen yol kalınlığı). 


\section{BULGULAR}

Katılımcı bir yaklaşımla gerçekleștirilen tüm bu çalışmaların ve değerlendirmelerin ışı̆̆ında, ulaşımla ile ilgili temel bileşenlerde, coğrafi detay türlerinde, bu detayların adlandırılmalarında ve benzer şekilde bu coğrafi detayların özniteliklerinde, 2013 yılında yürütülen çalışmaya kıyasla farklılıklar oluştuğu tespit edilmiştir.

TUCBS'nin 2013 yılındaki ilk sürümünde duyurulmuş olan "Ulaşım Veri Teması" içerisinde Ulaşım Temel Sinıfları, Demiryolu, Denizyolu, Havayolu ve Karayolu olacak şekilde toplamda beş adet alt bileşen bulunmakta iken, 2018 yılında katılımcıların görüşleri doğrultusunda tanımlanan "Ulaşım Ağları Teması" alt bileşenleri arasına 'Kablolu Ulaşım Ağı' eklenerek bu sayı altıya yükselmiştir. İlgili sınıf adları Tablo 2'de belirtilmiştir. Her ne kadar kablolu ulaşım ağ INSPIRE'ın dökümantasyonunda belirtilmiş olsa da, güncelleme sırasında Ankara Büyükșehir Belediyesinden gelen katılımcının görüşleri bu süreçte etkili olmuştur.

Tablo 2. TUCBS ulaşım ağları sınıfları

\begin{tabular}{ll}
\hline $\mathbf{2 0 1 3}$ & $\mathbf{2 0 1 8}$ \\
\hline Ulaşım temel sınıfları & Ortak ulaşım elemanları \\
Demiryolu & Demiryolu ağı \\
Denizyolu & Su ulaşım ağı \\
Havayolu & Hava ulaşım ağı \\
Karayolu & Karayolu ağı \\
& Kablolu ulașım ağı \\
\hline
\end{tabular}

Bununla birlikte 2013 yılında gerçekleştirilen çalışmada alt bileşenler altında toplamda 50 nesne tipi (feature type) ve 33 ön tanımlı veri tablosu (codelist) tanımlanmış iken bu sayı 2018 yılında nesne tipinde 131 'e, ön tanımlı veri tablosunda ise 42'ye yükselmiştir. TUCBS Ulaşım Temasına yönelik olarak alt bileşen, detay tipi ve ön tanıml veri tablosu sayıları arasındaki karşılaştırma Tablo 3'te gösterilmiştir.

Tablo 3. TUCBS Ulaşım Teması 2013-2018 Karşılaştırması

\begin{tabular}{lcc}
\hline & $\begin{array}{c}\text { Ulaşım Veri } \\
\text { Teması } \\
\text { (2013) }\end{array}$ & $\begin{array}{c}\text { Ulaşım Ağları } \\
\text { Teması } \\
\text { (2018) }\end{array}$ \\
\hline $\begin{array}{l}\text { Alt bileşenler } \\
\begin{array}{l}\text { Nesne tipi } \\
\text { (feature type) }\end{array}\end{array}$ & 5 & $5+1$ \\
$\begin{array}{l}\text { Ön tanımlı veri } \\
\text { tablosu (codelist) }\end{array}$ & 33 & $26+105$ \\
\hline
\end{tabular}

2013 yılında belirlenmiş olan nesne tiplerinden yalnızca 26 adedi, ön tanımlı veri tablolarından ise 17 adedi 2018 yılında yapılmış olan çalışmada yer almıştır.
Söz konusu karşılaştırma yapılırken 2013 ve 2018 yılları veri temaları için hazırlanmış olan detay kataloglarından faydalanılmıştır. Bazı nesne tipi ve ön tanımlı veri tablolarının isimleri farklı olsa da kataloglarda belirtilen tanımlardan faydalanılarak aynı işleve sahip oldukları tespit edilmiştir. Örneğin TUCBS'nin 2013 yllındaki ilk sürümünde duyurulmuş olan "Karayolu" alt bileșeninin "YolNoktasi" isimli nesne tipi, detay kataloğunda 'Karayolu verisinde nokta geometrisi ile ifade edilen verilerin tutulduğu detay sınıfıdır' şeklinde tanımlanmıștır. Bunun yanında 2018 ylında tanımlanan "Karayolu Ağı" alt bileşeninin "KarayoluDugumNoktasi" isimli nesne tipi ise detay kataloğunda 'Íki yol bağlantısı arasındaki bağlantıyı temsil etmek veya bir servis istasyonu veya döner kavşak gibi önemli bir uzamsal nesneyi temsil etmek için kullanılan bir noktasal coğrafi nesnedir.' şeklinde tanımlanmıştır. İki tanım arasındaki anlam benzerliğinden ötürü, "YolNoktasi" ile "KaraYoluDugumNoktasi" nesne tiplerinin aynı görevi üstlendiği tespit edilmiştir.

2013 yılında tanımlanmış bazı ön tanımlı veri tablolarının 2018 yılında gerçekleştirilmiş olan güncelleme çalışmasında birden fazla ön tanımlı veri tablosuna ayrılabildiği de gözlemlenmiştir. Örneğin 2013 yılında tanımlanmış olan ve geçit ve envanterlere yönelik tanımları içeren "UlasimYapiTuru" ön tanımlı veri tablosunun, 2018 yılında yapılan çalışmada envanter tanımlarını içeren "EnvanterTuru" ve geçit tanımlarını içeren "GeçitKategorisi" şeklinde iki ayrı ön tanımlı veri tablosu şeklinde güncellendiği görülmektedir.

Benzer şekilde 2013 yılında tanımlanmış olan bazı ön tanımlı veri tablolarının, 2018 yllında güncellenmiş olan aynı işleve sahip ön tanımlı veri tabloları ile farklı değerler içerdiği görülmüştür. Örneğin, 2013 yılında tanımlanmış olan ve karayolunun kullanım türünü ifade eden "KarayoluTurTipi" ön tanıml veri tablosu, 2018 yılında "YolTuruDegeri" olarak güncellenmiştir. Güncelleme ile birlikte tablo içerisindeki değerlerin arttığı görülmüş olup söz konusu karşılaştırma Tablo 4'te gösterilmiştir. İki ön tanımlı veri tablosundaki ortak değerler yeşil renk ile belirtilmiştir.

Anlamsal ve işlevsel olarak açıkça eşleştirilemeyen nesne tipleri ve ön tanımlı veri tabloları, 2018 yılında gerçekleştirilmiş olan güncelleştirme çalışmasında değiştirilmiş veya yeni üretilmiş olarak varsayılmıştır.

Bu kapsamlı güncelleme çalışmasında 2013 ve 2018 yılındaki TUCBS sürümlerinin nesne tiplerinin (feature type) ve ön tanımlı veri tablolarının (code list) karşılaştırmasına yönelik olarak hazırlanmış olan tablo, tüm paydaşların erişimine açık olarak olarak sunulmuştur (Bilgin 2020). Tabloda 2013 ve 2018 yıllarında duyurulmuş olan nesne tipi ya da ön tanımlı veri tablosunun aynı veya benzer amaçla kullanıldığına kanaat getirildiği durumlarda, iki farklı sürümdeki ilgili nesne tipi ya da ön tanımlı veri tablosu aynı renk ile gösterilmiştir. 
Tablo 4. KarayoluTurTipi - YolTuruDegeri Ön Tanımlı Veri Tablosu Karşılaștırması

\begin{tabular}{ll}
\hline KarayoluTurTipi & YolTuruDegeri \\
(2013) & (2018) \\
\hline agirVasitaYolu & acikKavsak \\
arabaParkGirisi & bisikletYolu \\
baglantiYolu & bolunmemisYol \\
bisikletYolu & bolunmusYol \\
diger & cevreYolu \\
gecitYol & donelKavsak \\
genisCevreYolu & otoparkGirisveCikis \\
otoyolu & otoyol \\
servisGirisi & otoyolBaglantiYolu \\
servisYolu & parkiciYol \\
tarlaYolu & patika \\
trafigeKapaliYol & servisYolu \\
yayaYolu & tesisGirisveCikis \\
& topluTasimayaTahsisliYol \\
& trafigeKapaliAlan \\
& traktorYolu \\
& yayaYoluZonu \\
& yuruyusYolu \\
\hline
\end{tabular}

Her ne kadar 2018 yılında gerçekleștirilen TUCBS çalışmaları katılımcı bir yaklaşımla gerçekleștirilmiş olsa da Hava Ulaşım Ağı ve Su Ulaşım Ağı ile ilgili çalışmalara ilgili kurum temsilcileri katılım sağlayamadığından bu alt bileşenler için INSPIRE'ın ulaşım temasındaki veri modeli benimsenmiştir.

Toplamda 6 alt bileșen, 131 detay tipi ve 42 ön tanımlı veri tablosu oluşturulmuştur ve bunların 2013'te gerçekleștirilen çalışmayla benzer ve farklı yönleri belirlenmiştir (Bilgin, 2020). Benzer şekilde özel sektörden katılımcıların da sürece dâhil edilmeleriyle, ulaşım teması kapsamında üretilen verinin tam anlamıla kamuya mal edilebileceği değerlendirilmektedir.

\section{SONUÇLAR}

Günümüzde ulaşım veri teması; günlük ev ve iş arasındaki ulaşım hareketlerinin yönetiminde, lojistik yönetiminden iş toplantılarına katılmak gibi planlama gerektiren işlerin gerçekleștirilmesinde, ulaşım planlamasından büyük ölçekli yatırımların planlanmasına kadar birçok farklı alanda önem arz etmektedir. Dolayısıyla ulaşımla ilişkili coğrafi veri setleri, büyük miktarda ve hızlı bir şekilde üretilmektedir. $\mathrm{Bu}$ verinin kamuya açık olarak paylașılmasının ve dolayısıyla işlenip değerlendirilmesinin ekonomiye olumlu yönde katkı sağlayacağı bir gerçektir.

2013 yllında belirlenmiş olan ulaşım temasına ilişkin alt bileșenlerin, nesne tiplerinin ve ön tanımlı veri tablolarının, 2018 yllında coğrafi veri üreten birçok kurum ve kuruluş temsilcisinin katılımıyla gerçekleştirilen güncelleme çalışmasında ne denli artış gösterdiği açıktır. Daha da önemlisi şu an önerilen veri modeli pratikte uygulanan süreçlerle daha iyi bir uyum içerisindedir.

$\mathrm{Bu}$ noktada da ulaşım altyapısını ilgilendiren verinin standartlara uygun bir şekilde üretilip, tüm paydaşlarla paylaşılmasının ve bütün bu sürecin katılımcı bir yaklaşımla yönetilmesinin ne kadar önem taşıdığı anlaşılmaktadır. Nitekim, coğrafi verinin paylaşımı için tüm teknik altyapı hazır olsa ve mevcut veri paylaşllyyor olsa bile, bunu değerlendirmek isteyecek kişi sayısı, bu kişilerin teknik yetkinliği ve tecrübesi yetersiz kalıyorsa, sistemin sürdürülebilir bir yapıda idame ettirilmesi büyük oranda sekteye uğrayacaktır.

Ulaşım veri teması ve ilișkili verinin herhangi bir koşul gözetmeksizin açılması (open by default yaklaşımı) ilk adımdır, ancak yeterli değildir. Aynı zamanda, belirli hedefler dahilinde (open with purpose yaklaşımı) açılmasının da gerekliliği görülmektedir (URL 5). Uluslararası arenada da buna benzer bir yaklaşımın benimsendiği görülmektedir. Veri bilimi ile uğraşan birçok araştırmacının katıldı̆̆ "Knowledge Discovery and Data Mining (KDD)" gibi önde gelen konferanslarda yarışmalar düzenlenmektedir ve bu yarışmalarda gerçek hayatta karşılaşılan bir problemin tanımı yapılmaktadır ve ilgili veri setleri yarışmacılarla paylaşılmaktadır. Örnek olarak 2019 yllında gerçekleștirilen KDD Cup yarışmasına 39 ülkeden 5000 'in üzerinde katılımcı üç farklı yarışma alanında çözümlerini sunmuş̧tur (URL 6).

Katılımcıların çabalarıyla ortaya konan değerli önerilerin, bir kuruma nasıl fayda sağladığının anlaşılması neticesinde, coğrafi veri setleriyle ilgilenen diğer kurumlarımızın da benzer yolu tercih etmelerinin önü açılmış olacaktır. Bir başka deyişle, bir kurum için değer yaratan bir çalışma, diğer kurumlar için de referans niteliği taşıyacaktır.

Ulaşım ilişkili veri setleri; navigasyon, rota planlama vb. birçok ticari uygulamada yoğun olarak kullanılan ve ticari değeri yüksek verilerdir. Kamu kurumlarının ürettiği verilerin güncelliği ve yaşatılmasındaki eksiklikler dikkate alındığında; özel sektörden, aktif ve pasif algılayıcılardan gelen verinin bütünleşik yönetilmesi, güncellenmesi ve birçok sektöre yönelik uygulamalarda gerçek zamanlı karar destek sağlaması gereklilik arz etmektedir.

\section{TEŞEKKÜR}

Çevre ve Şehircilik Bakanlığı, Coğrafi Bilgi Sistemleri Genel Müdürlüğü'ne, ulaşım veri teması ilişkili kurum temsilcileri ile yapılan toplantıları koordine etmesinden dolayı; anketin hazırlanmasındaki katkıları için Azer İlgar'a ve toplantıların yönetimini sağladığı için Yalın Yener'e teşekkür ederiz. 


\section{KAYNAKÇA}

Aydinoğlu, A. C.. ve Kara, A. (2019). Modelling and publishing geographic data with model-driven and linked data approaches: case study of administrative units in Turkey. Journal of Spatial Science, 64(1), 11-31.

Ballis, A. (2006). Implementing the European Transport Information System. Transportation Research Record, 1957(1), 23-31.

Bilgin, G. (2020). TUCBS 2013-2018 Sürümleri Karşılaştırma Tablosu https://github.com/gokhanbilgin/TUCBS/raw/master/TUCBS_Karsilastir ma.pdf (Son erişim tarihi: 29 Nisan 2020)

Borzacchiello, M. T., Torrieri, V. ve Nijkamp, P. (2009). An operational information systems architecture for assessing sustainable transportation planning: principles and design. Evaluation and Program Planning, Evaluating the Impact of Transport Projects: Lessons for Other Disciplines, 32(4), 381-389.

Chen, H. ve Cohn, A. G. (2011). Buried Utility Pipeline Mapping Based on Multiple Spatial Data Sources: A Bayesian Data Fusion Approach. Proceedings of the Twenty-Second International Joint Conference on Artificial Intelligence - Volume.3, 2411-2417.

Craglia, M. ve ark. (2012). Digital Earth 2020: towards the vision for the next decade. International Journal of Digital Earth, 5(1), 421.

Çevre ve Şehircilik Bakanlığı. (2019). 2020-2023 Ulusal Akıllı Șehirler Stratejisi ve Eylem Planı, https://www.akillisehirler.gov.tr/wpcontent/uploads/EylemPlani.pdf (Son erişim tarihi: 29 Nisan 2020)

Eisenberg, J. N. S. ve ark. (2006). Environmental change and infectious disease: How new roads affect the transmission of diarrheal pathogens in rural Ecuador. Proceedings of the National Academy of Sciences, 103(51).

Goodchild, M. F., Fu, P. ve Rich, P. (2007). Sharing Geographic Information: An Assessment of the Geospatial One-Stop. Annals of the Association of American Geographers, 97(2), 250-266.

Gunay, A., Akcay, O. ve Altan, M. O. (2014). Building a semantic based public transportation geoportal compliant with the INSPIRE transport network data theme. Earth Science Informatics, 7(1), 2537.
Güney, C., Doğru, A. Ö., Başaraner, M., Çelik, R. N., Uluğtekin, N., Özlüdemir, T., ve Keskin, M. (2015). TUCBS Açmazı ve Açık Bir Ulusal Mekânsal Veri Altyapısına Yönelim. TMMOB Harita ve Kadastro Mühendisleri Odası, 15. Türkiye Harita Bilimsel ve Teknik Kurultayı, 2528 Mart 2015, Ankara.

Hickman, R. ve Dean, M. (2018). Incomplete cost incomplete benefit analysis in transport appraisal. Transport Reviews, 38(6), 689-709.

INSPIRE. (2007). A quick overview for implementers INSPIRE. https://inspire.ec.europa.eu/quickoverview-implementers/57528 (Son erişim tarihi: 1 Mayıs 2020)

INSPIRE. (2014). D2.8.I.7 Data Specification on Transport Networks - Technical Guidelines. https://inspire.ec.europa.eu/file/1723/downl oad?token=0GOYYbMF (Son erişim tarihi: 1 Mayıs 2020)

Karlaftis, M. ve Kepaptsoglou, K. (2012). Performance measurement in the road sector: A cross-country review of experience (Working Paper No: 2012-10). International Transport Forum Discussion Paper.

Kesten, A. S. ve Öğüt, K. S. (2014). A New Passenger Oriented Performance Measurement Framework for Public Rail Transportation Systems. Promet - Traffic\&Transportation, 26(4), 299-311.

Pickrell, S. ve Neumann, L. (2001). Use of Performance Measures in Transportation Decision Making, Transportation Research Board Conference Proceedings, 26, 17-33.

Proffitt, D. G., Bartholomew, K., Ewing, R. ve Miller, H. J. (2019). Accessibility planning in American metropolitan areas: Are we there yet? Urban Studies, 56(1), 167-192.

Tait, M. G. (2005). Implementing geoportals: applications of distributed GIS. Computers, Environment and Urban Systems, Geoportals, 29(1), 33-47.

Ulaştırma, Denizcilik ve Haberleşme Bakanlığı. (2014). 2014-2023 Ulusal Akıllı Ulaşım Sistemleri Strateji Belgesi, https://hgm.uab.gov.tr/uploads/pages/akilliulasim-sistemler-aus/aus.pdf (Son erişim tarihi: 29 Nisan 2020)

Ulutaş, D., Kara, G. ve Cömert, Ç. (2016). Semantic definition and matching for implementing national spatial data infrastructures. Journal of Spatial Science, 61(2), 441-459. 
URL-1:

https://www.resmigazete.gov.tr/eskiler/2018 /07/20180710-1.pdf (Son erișim tarihi: 2 Nisan 2020)

URL-2:

https://www.resmigazete.gov.tr/eskiler/2011 /07/20110704M1-1.htm. (Son erişim tarihi: 2 Nisan 2020)

URL-3: $\quad$ https://cbs.csb.gov.tr/veri-temalarihakkinda-i-86103. (Son Erişim: 2 Nisan 2020)

URL-4: https://cbs.csb.gov.tr/cografi-veri-temalariuygulama-semalari-i-86098 (Son Erişim: 2 Nisan 2020)

URL-5: http://geothink.ca/geothinklearn-13-theevolution-of-open-data-in-canada/ (Son erișim: 2 Nisan 2020)
URL-6: https://www.kdd.org/kdd2019/kdd-cup (Son erişim tarihi: 2 Nisan 2020)

Varol, M.B., ve Șanlıoğlu, İ. (2017). Open Geospatial Consortium Web Map and Feature Services and Free/Open Source Server/Client Softwares. International Journal of Engineering and Geosciences 2 (1): 17-26.

Yang, X., Li, X., Ning, B. ve Tang, T. (2016). A Survey on Energy-Efficient Train Operation for Urban Rail Transit. IEEE Transactions on Intelligent Transportation Systems, 17(1), 2-13.

Yllmaz, A. ve Canıberk, M. (2018). Real Time Vector Database Updating System: A Case Study for Turkish Topographic Vector Database (TOPOVT). International Journal of Engineering and Geosciences, 3(2), 73-79. 